\title{
Influence of Organic Esters on Portland Cement Hydration and Hardening
}

\author{
Duan-le Li, ${ }^{1}$ Da-peng Zheng, ${ }^{1}$ Dong-min Wang $\mathbb{D}^{1},{ }^{1}$ Ji-hui Zhao, ${ }^{2}$ Cheng Du, ${ }^{1}$ and \\ Cai-fu Ren ${ }^{1}$ \\ ${ }^{1}$ School of Chemical and Environmental Engineering, China University of Mining and Technology, Beijing, China \\ ${ }^{2}$ Department of Civil Engineering, Tsinghua University, Beijing, China \\ Correspondence should be addressed to Dong-min Wang; wangdongmin-2008@163.com
}

Received 25 May 2017; Revised 24 September 2017; Accepted 8 November 2017; Published 14 January 2018

Academic Editor: Francisca Puertas

Copyright (c) 2018 Duan-le Li et al. This is an open access article distributed under the Creative Commons Attribution License, which permits unrestricted use, distribution, and reproduction in any medium, provided the original work is properly cited.

\begin{abstract}
This paper investigated the effect of organic compounds with ester groups on the hydration and hardening of cement. The effects of five kinds of organic compounds with ester groups (ethyl acetate, dimethyl oxalate, glyceryl triacetate, trimethyl phosphate, and triethanolamine borate) on hydration heat, hydration degree, setting time, mechanical properties, microstructure, and pore structure of hardened cement slurry were studied. The test results showed that esters can make the end time of cement hydration induction longer and delay the occurrence of the second exothermic peak. Also, the effect of five kinds of esters on the hydration and hardening of cement was basically followed by TG> TB $>$ DMO $>$ EAC $>$ TMP. In terms of molecular structure, for organic compounds containing only ester groups, the higher the number of ester groups, the greater the effect on the hydration of cement. The introduction of other functional groups (such as phosphate or borate) will influence the effect of the esters.
\end{abstract}

\section{Introduction}

In recent decades, the new progress in the preparation and application of cement concrete materials has benefited from the development and effective application of chemical admixtures. At present, the chemical admixture has become a cement-based material, which is an important regulatory component or modification method. Addition of a small amount of admixture, especially organic admixture, can effectively adjust the performance of cement-based materials, such as improving work performance or rheology, speeding up or delaying the hydration rate and coagulation time, and improving the physical and mechanical properties and durability of materials [1-5]. The performance of the admixture has an important relationship with the functional groups in its molecule. At present, the functional groups or functional groups contained in the organic admixtures used in the concrete materials mainly include hydroxyl groups, carboxyl groups, amino groups, and sulfonic acid groups [6-9].

In addition, it should be noted that the ester groups and phosphonate groups are also important functional groups.
On the one hand, the ester-based organics can be used as antifoaming agents. On the other hand, many studies have reported that the esterification modification method is an important means for improving or modifying the performance of hydroxyl- or carboxyl-containing admixtures $[1,10]$. In view of the low grinding ability of triethanolamine in cement fine-grinding stage and the disadvantage on the late strength growth of cement, it is studied that the triethanolamine modified by carboxylic acid has a better effect on the grinding and dispersing, and the strength of cement at early and late stage has a significant growth $[1,11,12]$. The molecular structure and dosages of the admixtures play an important role in the hydration of cement, such as shorting the hydration time, reducing the hydration heat, and improving the mechanical strength [13-16]. However, it is not clear at present that the increase in the performance of the admixture is caused by changes in the molecular structure or by the action of the newly introduced ester functional groups after modification. Also, there is no research at this point.

In order to explore whether the ester groups have an important effect on the hydration and hardening of cement, five common organic compounds, ethyl acetate, dimethyl 
TABLE 1: The chemical compositions and mineral compositions of cement wt\%.

\begin{tabular}{cccccccccccccc}
\hline $\mathrm{CaO}$ & $\mathrm{SiO}_{2}$ & $\mathrm{Al}_{2} \mathrm{O}_{3}$ & $\mathrm{Fe}_{2} \mathrm{O}_{3}$ & $\mathrm{MgO}$ & $\mathrm{SO}_{3}$ & $\mathrm{R}_{2} \mathrm{O}$ & $\mathrm{f}-\mathrm{CaO}$ & $\mathrm{LOI}$ & $\mathrm{C}_{3} \mathrm{~S}$ & $\mathrm{C}_{2} \mathrm{~S}$ & $\mathrm{C}_{3} \mathrm{~A}$ & $\mathrm{C}_{4} \mathrm{AF}$ \\
\hline 62.13 & 20.76 & 4.58 & 3.27 & 3.13 & 2.80 & 0.57 & 0.76 & 1.56 & 57.3 & 18.9 & 6.5 & 11.3 \\
\hline
\end{tabular}

TABLE 2: The physical properties of cement test results.

\begin{tabular}{|c|c|c|c|c|c|}
\hline \multirow[t]{2}{*}{ Specific surface area $/\left(\mathrm{m}^{2} \cdot \mathrm{kg}^{-1}\right)$} & \multirow[t]{2}{*}{ Standard consistency, \% } & \multicolumn{2}{|c|}{ Setting time $/ \mathrm{min}$} & \multicolumn{2}{|c|}{$\begin{array}{l}\text { Compressive } \\
\text { strength/MPa }\end{array}$} \\
\hline & & Initial & Final & $3 \mathrm{~d}$ & $28 \mathrm{~d}$ \\
\hline 347 & 27.2 & 155 & 215 & 28.3 & 51.2 \\
\hline
\end{tabular}

TABLE 3: Basic information of five kinds of ester group.

\begin{tabular}{|c|c|c|c|c|}
\hline Esters & Abbreviation & Chemical formula & Structure & Number of ester groups \\
\hline Ethyl acetate & EAC & $\mathrm{C}_{4} \mathrm{H}_{8} \mathrm{O}_{2}$ & & 1 \\
\hline Dimethyl oxalate & $\mathrm{DMO}$ & $\mathrm{C}_{4} \mathrm{H}_{6} \mathrm{O}_{4}$ & & 2 \\
\hline Glyceryl triacetate & TG & $\mathrm{C}_{9} \mathrm{H}_{14} \mathrm{O}_{6}$ & & 3 \\
\hline Trimethyl phosphate & TMP & $\mathrm{C}_{3} \mathrm{H}_{9} \mathrm{O}_{4} \mathrm{P}$ & & 3 \\
\hline Triethanolamine borate & TB & $\mathrm{C}_{6} \mathrm{H}_{12} \mathrm{BNO}_{3}$ & & 3 \\
\hline
\end{tabular}

oxalate, glyceryl triacetate, trimethyl phosphate, and triethanolamine borate, were selected for comparative experiments in this study. The effects of five kinds of organic compounds on hydration heat, hydration degree, setting time, mechanical properties, microstructure, and pore structure of hardened slurry were studied in this study.

\section{Materials and Methods}

2.1. Materials. Ordinary Portland cement, complying with the requirements of Chinese National Standard GB 175-2007 (common Portland cement), was used for all experiments here. The chemical composition and mineral composition of cement are shown in Table 1, and the physical properties of cement are shown in Table 2. The five esters selected for the experiment were ethyl acetate (EAC), dimethyl oxalate (DMO), glyceryl triacetate (TG), trimethyl phosphate (TMP), and triethanolamine borate (TB), and their basic information is shown in Table 3.

2.2. Hydration Heat of Cement Paste. In this study, the hydration heat of cement paste was tested using an eightchannel micro-heat instrument (TAM-Air).

2.3. Hydration Degree of Cement. The hydration degree of cement was characterized by chemical-bound water and calcium hydroxide content. The prepared cement samples were maintained under the standard curing conditions to the corresponding age $(3 \mathrm{~d}$ and $28 \mathrm{~d})$, then the central portion was removed and the hydration was terminated with absolute ethanol. The samples were burned at $1000^{\circ} \mathrm{C}$ in the muffle furnace for $2 \mathrm{~h}$ to constant weight, and the mass loss of the samples was chemical-bound water. In addition, TG/DTA6300 thermogravimetric analyzer was used to test samples, and due to the decomposition of calcium hydroxide, the sample will have a significant mass loss at $400^{\circ} \mathrm{C}-500^{\circ} \mathrm{C}$, and the content of calcium hydroxide in the sample can be calculated.

2.4. Morphology and Pore Structure of Hydration Product. The morphology of cement hydration products was observed by JSM-6700F scanning electron microscopy, and the pore structure was measured by AutoPore IV 9500 mercury porosimeter.

2.5. Workability and Mechanical Properties of Cement. The standard consistency water consumption and setting time of cement are in accordance with GB/T 1346-2001 "cement standard consistency of water consumption, setting time, stability test method," and the cement mortar strength is in accordance with GB/T 17,671-1999 "cement mortar strength test method" (ISO method). 


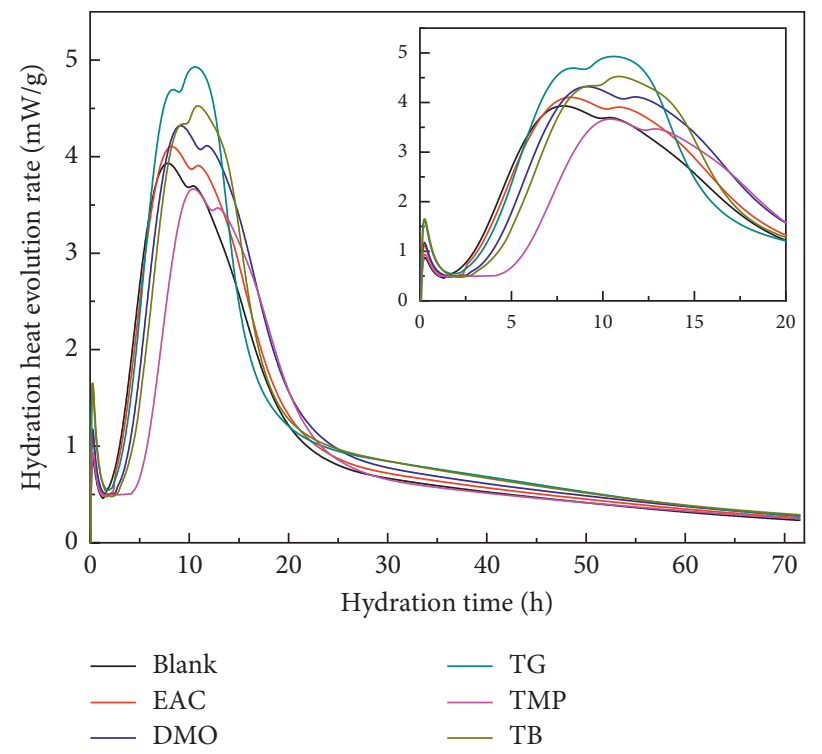

FIGURE 1: Effect of ester on the rate of heat release of cement hydration.

TABle 4: Characteristic parameters of cement hydration.

\begin{tabular}{|c|c|c|c|c|c|c|}
\hline \multirow[t]{2}{*}{ Sample } & \multirow{2}{*}{$\begin{array}{l}\text { The end time of the induction } \\
\text { period }(\mathrm{h})\end{array}$} & \multirow{2}{*}{$\begin{array}{l}\text { The appear time of the second } \\
\text { exothermic peak }(\mathrm{h})\end{array}$} & \multirow{2}{*}{$\begin{array}{l}\text { Second exothermic peak } \\
\text { exothermic rate }(\mathrm{J} / \mathrm{g} \cdot \mathrm{h})\end{array}$} & \multicolumn{3}{|c|}{$\begin{array}{c}\text { Total heat release } \\
(\mathrm{J} / \mathrm{g})\end{array}$} \\
\hline & & & & $24 \mathrm{~h}$ & $48 \mathrm{~h}$ & $72 \mathrm{~h}$ \\
\hline $\begin{array}{l}\text { Pure } \\
\text { cement }\end{array}$ & 1.3 & 7.9 & 14.2 & 295.0 & 374.0 & 416.6 \\
\hline $\begin{array}{l}+0.05 \% \\
\text { EAC }\end{array}$ & 1.7 & 8.3 & 14.8 & 311.3 & 396.8 & 443.5 \\
\hline $\begin{array}{l}+0.05 \% \\
\text { DMO }\end{array}$ & 2.2 & 9.2 & 15.6 & 325.6 & 418.1 & 468.4 \\
\hline $\begin{array}{l}+0.05 \% \\
\text { TG }\end{array}$ & 1.8 & 10.6 & 17.7 & 330.0 & 430.1 & 482.2 \\
\hline $\begin{array}{l}+0.05 \% \\
\text { TMP }\end{array}$ & 4.2 & 10.4 & 13.2 & 266.7 & 345.2 & 389.0 \\
\hline $\begin{array}{l}+0.05 \% \\
\text { TB }\end{array}$ & 2.2 & 10.9 & 16.3 & 311.8 & 411.2 & 463.7 \\
\hline
\end{tabular}

\section{Results and Discussion}

3.1. Effect of Ester on Hydration Heat of Cement. The amount of all kinds of esters was set to $0.05 \%$ by mass. Figure 1 shows exothermic rate curves during the hydration of pure cement paste and cement paste containing five kinds of ester. The variation of the characteristic parameters is shown in Table 4. It can be seen from Figure 1 and Table 4 that cement hydration exothermic rate and heat release are significantly changed after the addition of ester. First of all, the addition of five kinds of ester makes cement hydration induction time longer and postpone the appear time of the second exothermic peak. Also, with the increase of the number of ester groups, the appear time of the second exothermic peak of cement paste delays. The addition of TG and TB resulted in a delay of 2.7 and 3.05 hours for the appear of the second exothermic peak. The results showed that the ester had a delayed effect on the hydration reaction rate of cement at the early stage $(<10 \mathrm{~h}$, hydration induction period and hydration acceleration period).

However, in addition to TMP, the other four kinds of esters improve the second exothermic peak of cement. When adding $0.05 \%$ TG to cement, the peak is raised from 14.15 to $17.74 \mathrm{~J} / \mathrm{g} \cdot \mathrm{h}$. The degree of effect was as follows: TG (3 ester groups)> TB ( 3 ester groups) $>$ DMO (2 ester groups) $>$ EAC (1 ester group). It indicates that the four esters will delay the early hydration reaction but will also promote the degree of response during the acceleration phase. TMP has a delayed effect on cement hydration and reduces the second exothermic peak, the reason may be that its molecular structure contains phosphorus.

The total amount of heat release in different hydration stages also shows a similarity to the second exothermic peak, 


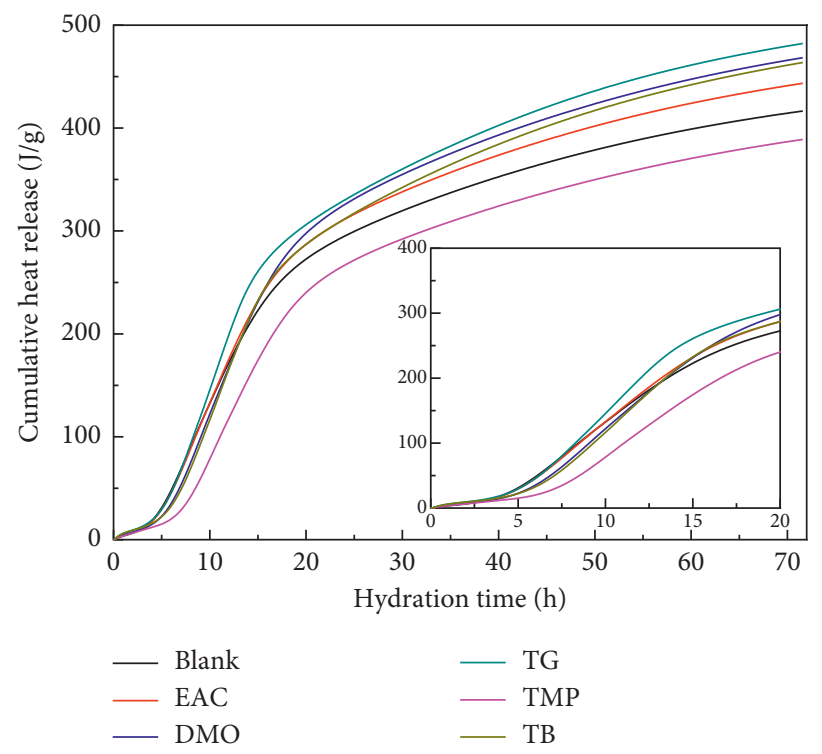

FIgURE 2: Effect of ester on the total heat release of cement hydration.

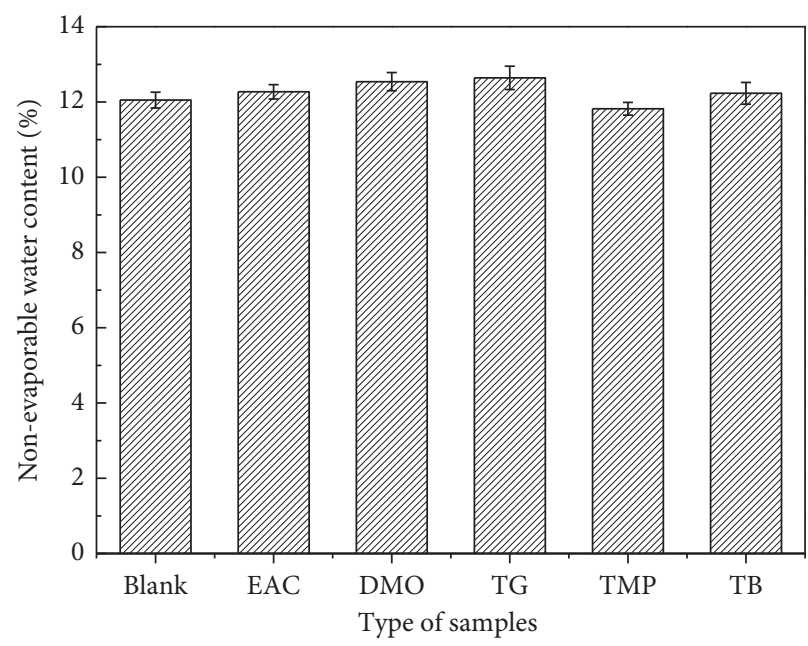

(a)

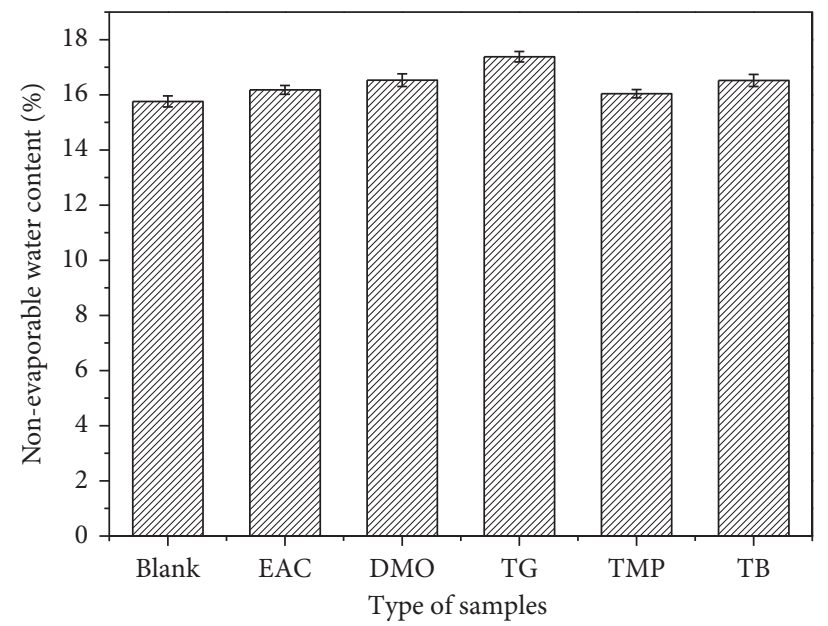

(b)

FIGURE 3: Effect of ester on nonevaporation water content of cement paste: (a) $3 \mathrm{~d}$ and (b) $28 \mathrm{~d}$.

as can be seen from Figure 2, TG, TB, DMO, and EAC can improve the total amount of heat release in $24 \mathrm{~h}, 48 \mathrm{~h}$, and $72 \mathrm{~h}$, and the greater the number of ester groups, the stronger the effect.

\subsection{Effect of Ester on Cement Hydration Degree. Nonevaporable} water content is usually used to characterize the degree of cement hydration. In the previous section, the hydration heat analysis speculated that, in addition to TMP, the other four kinds of organic compounds can promote the early hydration of cement. This section uses the results of nonevaporative hydration to verify that the above assumptions are correct. Figure 3 shows two histograms of the nonevaporable water content of the cement slurry with different contents of ester at $3 \mathrm{~d}$ and $28 \mathrm{~d}$. It can be seen from Figure 3(a) that TG, TB, DMO, and EAC, four kinds of organic compounds, can improve the nonevaporative water content of cement at $3 \mathrm{~d}$. TG can increase the nonevaporable water content by $4.9 \%$, while TMP will reduce the nonevaporative water content of cement by $1.9 \%$, this is consistent with the laws of hydration heat. It can be analyzed from Figure 2(b) that the five kinds of ester can obviously improve the content of nonevaporable water content of cement at $28 \mathrm{~d}$. Based on the above analysis, the ester can improve the hydration degree of the cement, and the effect of promotion from large to small is: $\mathrm{TG}>\mathrm{DMO}>\mathrm{TB}>\mathrm{EAC}>$ 


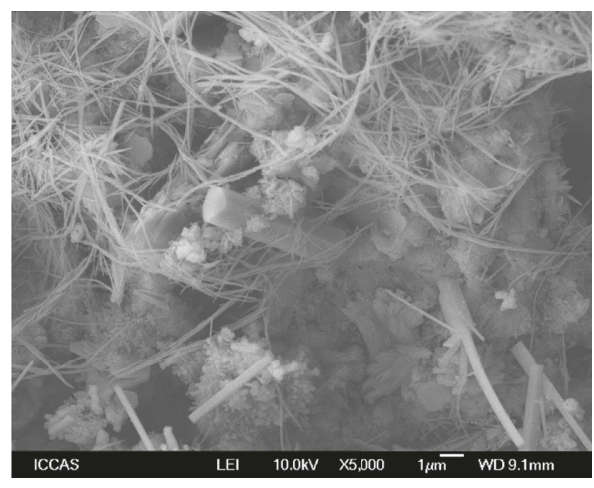

(a)

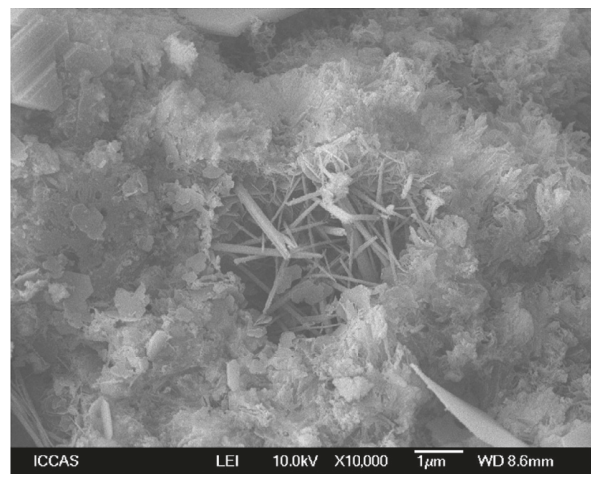

(c)

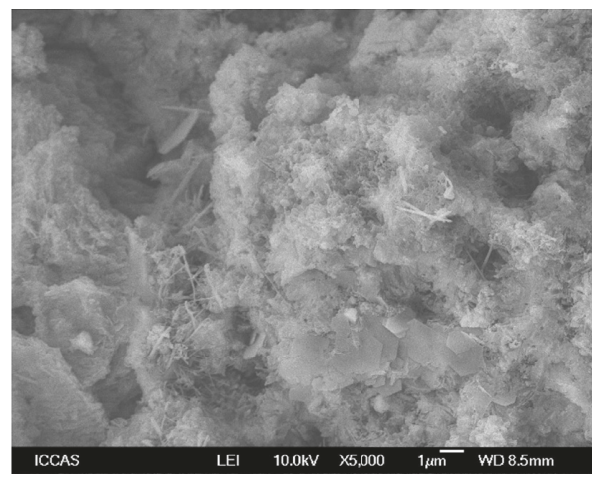

(e)

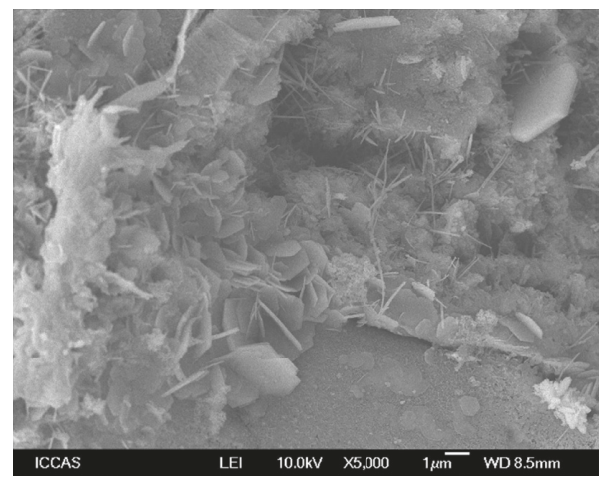

(b)

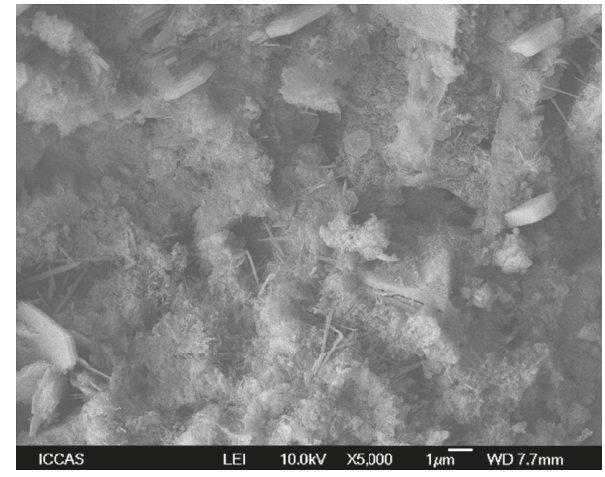

(d)

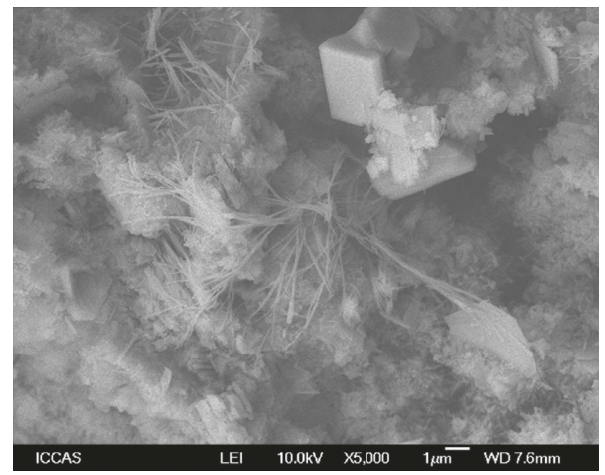

(f)

Figure 4: The hydration products morphology of different hardened cement at $3 \mathrm{~d}$. (a) Blank. (b) $+0.05 \%$ EAC. (c) $+0.05 \%$ DMO. (d) $+0.05 \%$ TG. (e) $+0.05 \%$ TMP. (f) $+0.05 \%$ TB.

TMP. TG has the best effect and can increase the nonevaporable water content of cement by $10.3 \%$ at $28 \mathrm{~d}$.

Compared with the molecular structure of five kinds of organic compounds, EAC, DMO, and TG belong to the same series of organic matter with increasing number of ester groups, while TB and TMP contain three ester groups as in TG, but both contain boronic acid groups and phosphoric acid groups, respectively. It can be inferred that the higher the number of ester groups contained in the organic matter containing only the ester functional groups, the greater the effect on the degree of hydration of the cement. Also, the introduction of other functional groups (such as phosphate or borate) will have some influence on the effect of ester organic matter.

3.3. Effects of Ester on the Morphology of Cement Hydration Products. The effects of ester on the morphology of hydrated products of cement at $3 \mathrm{~d}$ and $28 \mathrm{~d}$ are shown in Figures 4 and 5, respectively. It can be seen from Figure 4 that a large amount of hydrated products such as ettringite (AFt), CSH gel, and $\mathrm{Ca}(\mathrm{OH})_{2}$ have been produced in the six kinds of cement slurries at the age of $3 \mathrm{~d}$, but the structure is relatively loose and porous, indicating that the overall degree of 


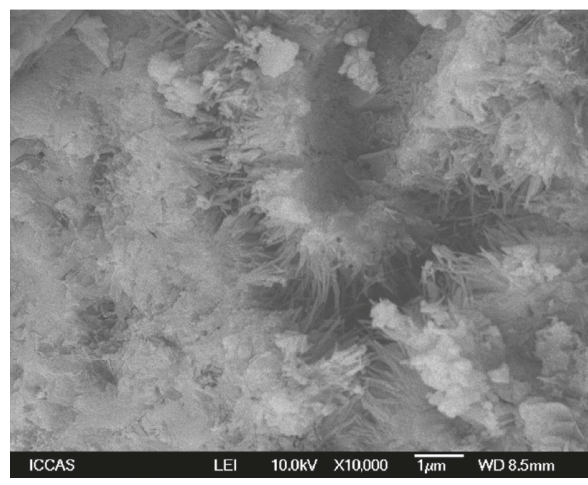

(a)

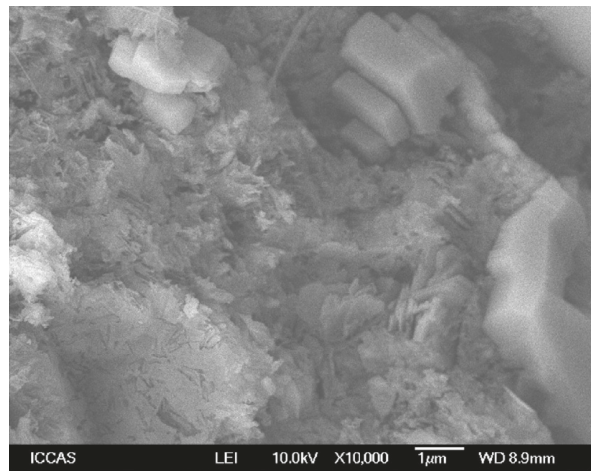

(c)

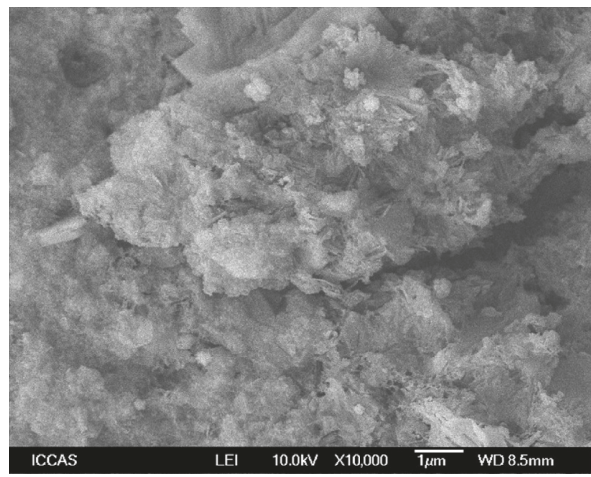

(e)

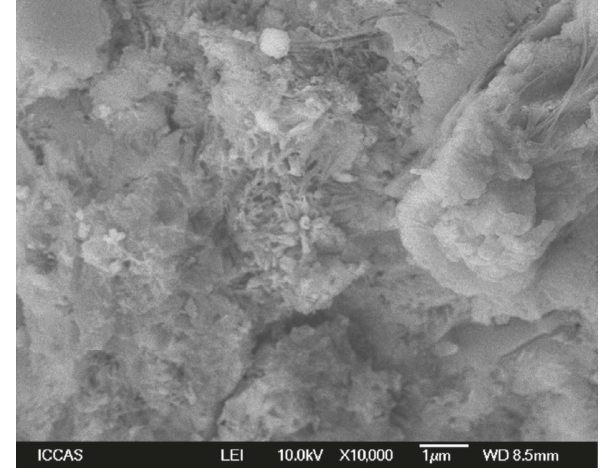

(b)

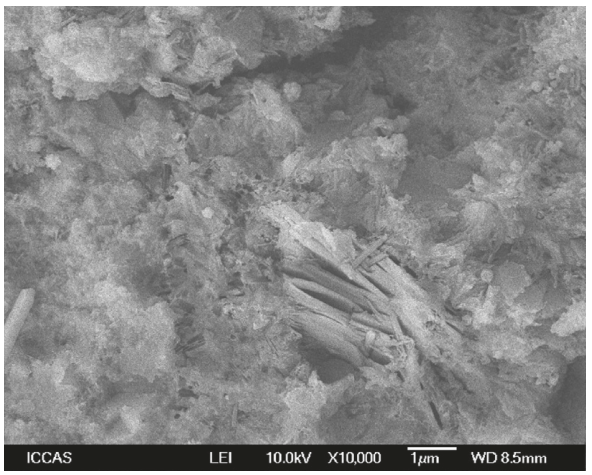

(d)

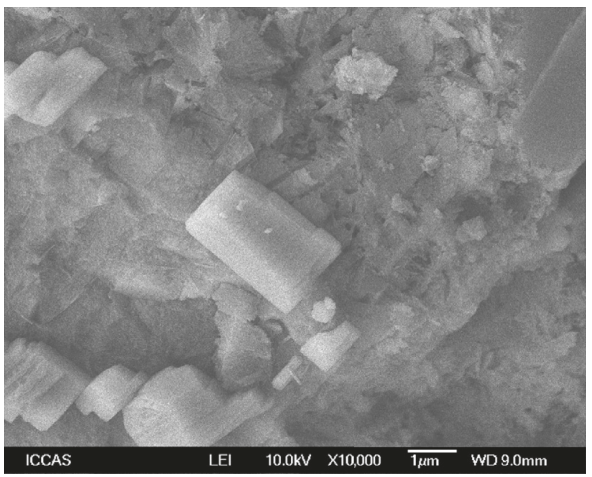

(f)

FIgURE 5: The hydration products morphology of different hardened cement at $28 \mathrm{~d}$. (a) Blank. (b) $+0.05 \%$ EAC. (c) $+0.05 \%$ DMO. (d) $+0.05 \%$ TG. (e) $+0.05 \%$ TMP. (f) $+0.05 \%$ TB.

hydration is not deep. Compared with the blank group, the hydration products of cement-hydrated products with EAC, DMO, TG, and TB were relatively dense, and the large amount of $\mathrm{C}-\mathrm{S}-\mathrm{H}$ gel was formed to encapsulate ettringite, and there are more $\mathrm{Ca}(\mathrm{OH})_{2}$ generation. It was suggested that the addition of these four kinds of organic compounds promoted the formation of hydration products of cement at $3 \mathrm{~d}$, in which TG and DMO had the most obvious effect. In contrast, the structure of cement with TMP is very loose, and the formation of hydration products is less, indicating that TMP has an inhibitory effect on the hydration of cement.
It can be seen from Figure 5 that $\mathrm{CSH}$ gel has been connected with one in each group of cement paste at $28 \mathrm{~d}$ and AFt is wrapped in it. The size and amount of $\mathrm{Ca}(\mathrm{OH})_{2}$ increased, and the density was significantly higher than the $3 \mathrm{~d}$ age. The density of the cement paste in each group was as follows: $\mathrm{TG}>\mathrm{DMO}>\mathrm{TB}>\mathrm{EAC}>\mathrm{TMP}>$ blank group. The results showed that the five kinds of esters could promote the formation of hydration products of cement at $28 \mathrm{~d}$, and the effect was more obvious than that of $3 \mathrm{~d}$. Thus, it is further explained that these five kinds of organic compounds promote the cement hydration reaction and improve the degree of hydration at $28 \mathrm{~d}$. 


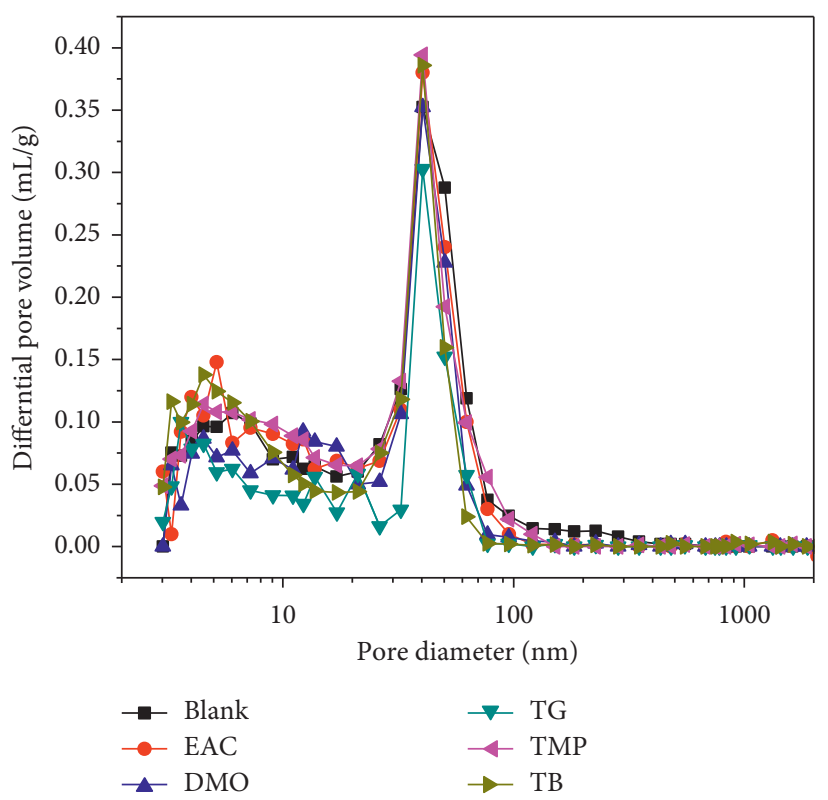

(a)

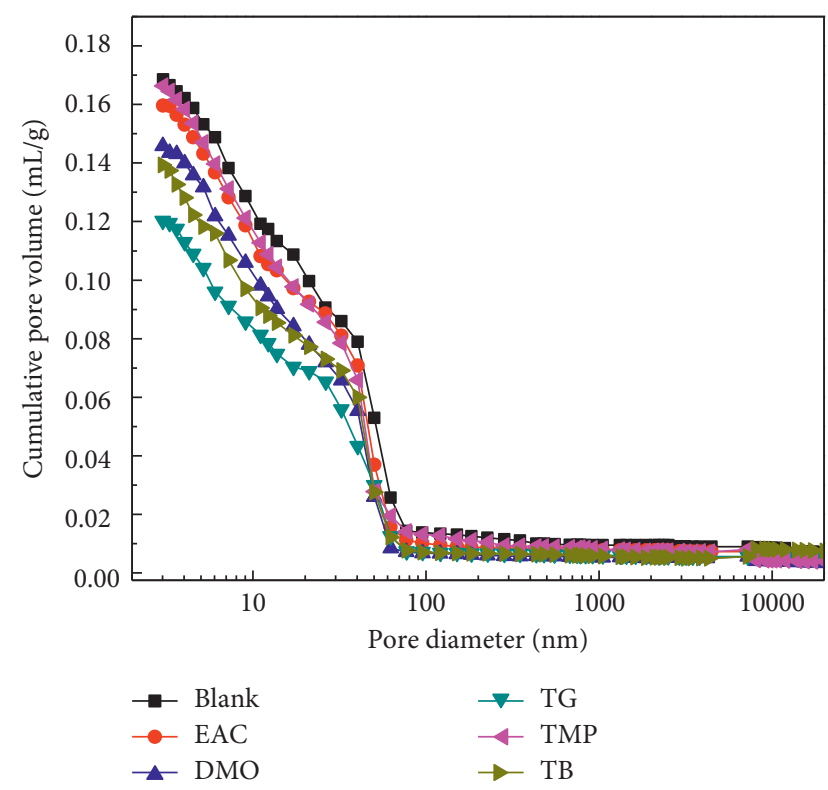

(b)

Figure 6: Pore volume distribution at different ages of hardened cement. (a) Differential distribution. (b) Cumulative distribution.

TABLE 5: Pore structural parameters of hardened cement.

\begin{tabular}{|c|c|c|c|c|c|}
\hline \multirow{2}{*}{ Sample } & \multirow{2}{*}{ Total pore volume $(\mathrm{mL} / \mathrm{g})$} & \multicolumn{4}{|c|}{ Distribution ratio of holes (\%) } \\
\hline & & $<20 \mathrm{~nm}$ & $20-50 \mathrm{~nm}$ & $50-200 \mathrm{~nm}$ & $>200 \mathrm{~nm}$ \\
\hline Blank & 0.17 & 40.9 & 27.6 & 24.1 & 7.4 \\
\hline EAC & 0.16 & 42.0 & 34.9 & 17.7 & 5.4 \\
\hline DMO & 0.15 & 46.5 & 30.7 & 13.7 & 9.1 \\
\hline TG & 0.12 & 42.7 & 32.4 & 19.4 & 5.5 \\
\hline TMP & 0.17 & 44.8 & 38.5 & 10.2 & 6.5 \\
\hline TB & 0.14 & 44.6 & 35.6 & 15.0 & 4.8 \\
\hline
\end{tabular}

3.4. Effects of Ester on the Pore Structure of Cement. SEM can only qualitatively observe the density of cement hydration product structure, and MIP can visually analyze the pore structure of cement hydration products quantitatively. The effect of ester on the pore size distribution of cement paste at $28 \mathrm{~d}$ is shown in Figure 6, and the characteristic parameters of pore structure are shown in Table 3 .

It can be seen from Figure 6 that the pore size of the hardened slurry is basically distributed in the range of less than $1000 \mathrm{~nm}$. The five kinds of cement slurries with esters are not the same as the blanks and are about $40 \mathrm{~nm}$. The most probable pore size of the five kinds of cement paste with organic matter was almost the same as that of the blank, and the total pore volume was significantly smaller than that of the blank group. TG significantly reduced the total pore volume of cement slurry, which was $28.7 \%$ lower than that of blank. TB and DMO decreased the total pore volume by $17.4 \%$ and $13.5 \%$, respectively. The effect of TMP on the total pore volume was the smallest, and the order of action is as follows: TG> TB $>$ DMO $>$ EAC $>$ TMP.

According to Renhe et al. [17], the pore in cement paste can be divided into four categories: much detrimental pores
(>200 nm), detrimental pores (50-200 nm), less harmful pore $(20-50 \mathrm{~nm})$, and innocuous pores $(<20 \mathrm{~nm})$. It can be seen from Table 5 that the five kinds of organic compounds have improved the content of innocuous pores and less harmful pore and significantly reduced the content of detrimental pores and much detrimental pores. This indicates that the five kinds of esters play a role in optimizing the pore size distribution of cement slurry, which is helpful to improve the macroscopic properties such as mechanical properties and durability of cement.

3.5. Effects of Ester on Mechanical Properties and Setting Time of Cement. The setting time of the cement slurry with different ester-based organic materials is shown in Figure 7. It can be seen from the results that the esters prolonged the initial setting time and final setting time of the cement, and the initial finishing time of the cement gradually prolonged with the increase of the ester. It is well explained by the results of the previous hydration heat that the five kinds of esters make the cement hydration induction end time longer and postpone the second exothermic peak, that is, the esters 


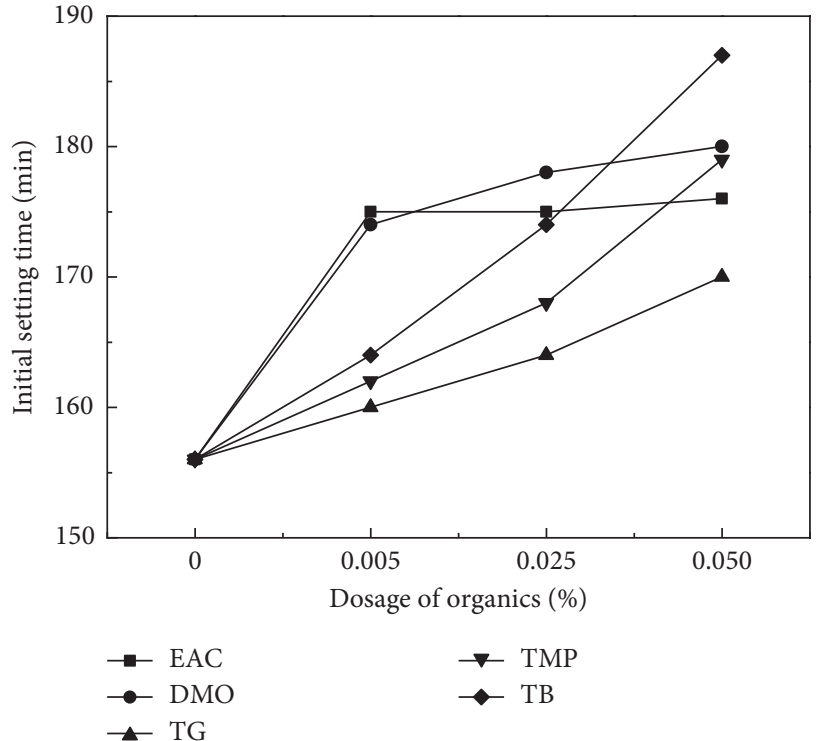

(a)

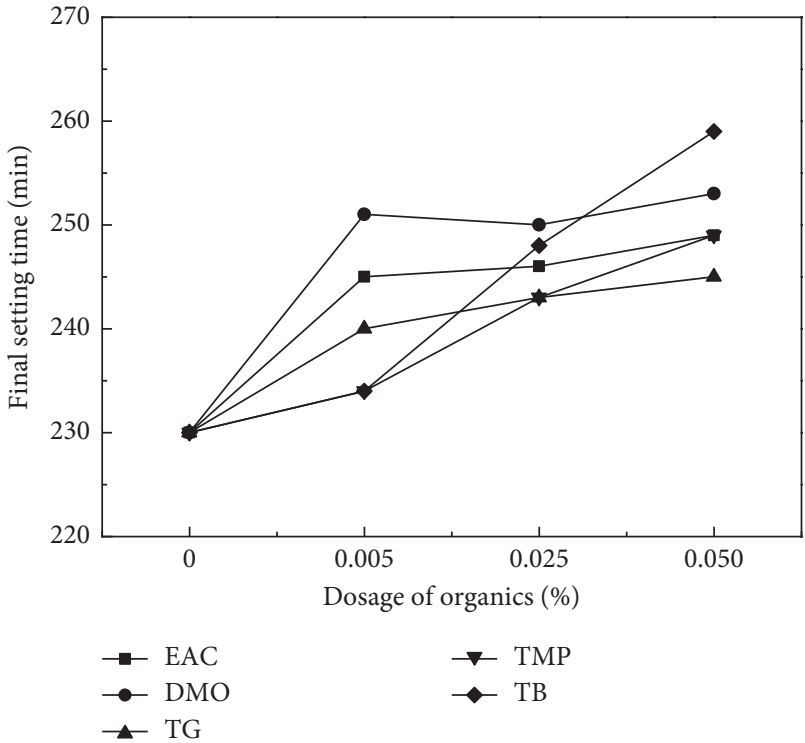

(b)

Figure 7: Effect of ester organics on the setting time of cement. (a) Initial setting time. (b) Final setting time.

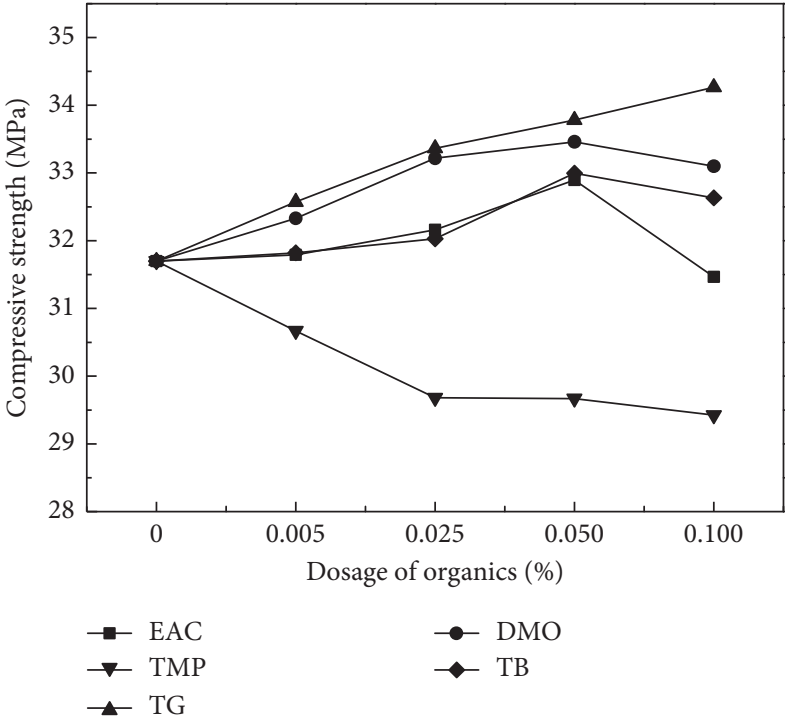

(a)

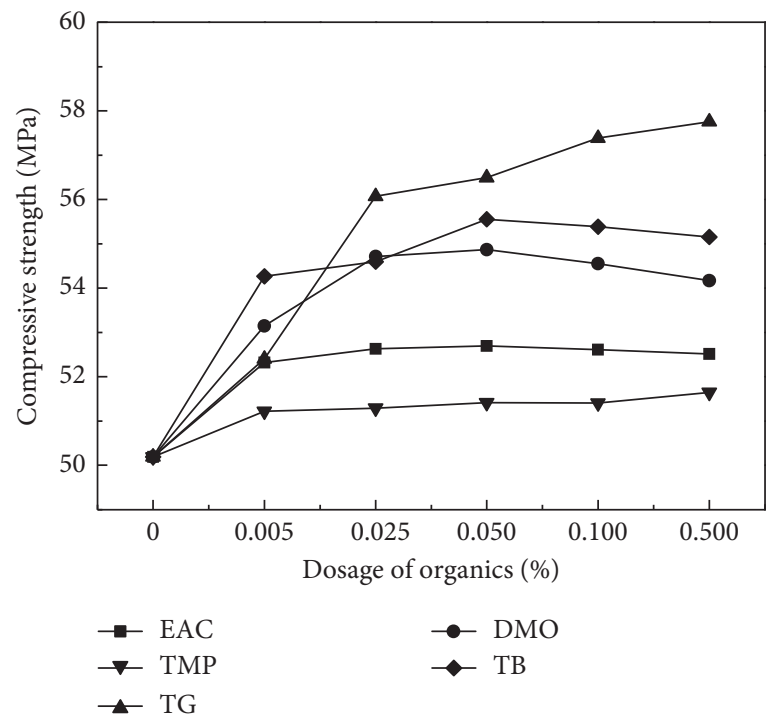

(b)

FIGURE 8: Effect of esters on the compressive strength of cement mortar. (a) 3d. (b) $28 \mathrm{~d}$.

have a delayed effect on the hydration reaction rate at the early stage of cement (hydration induction period and the acceleration period). When dosage is $0.05 \%$, the delay effect of TB on the coagulation time is most obvious. As can be seen from Figure 7, the initial setting time was delayed from 156 minutes to 187 minutes and the final setting time is delayed from 230 minutes to 259 minutes. Also, TG has the minimum retardation effect.

The effect of different content of ester on the compressive strength of cement mortar is shown in Figure 8. The $3 \mathrm{~d}$ strength of cement increased with the increase of EAC, DMO, TG, and TB contents. However, the strength of cement with EAC, DMO, and TB began to decrease after the content of $0.05 \%$, indicating that the best dosage of these three esters is $0.05 \%$. In contrast, the strength of cement mixed with TMP gradually decreased with the increase of organic matter content, which indicated that TMP was unfavorable to the development of cement $3 \mathrm{~d}$ strength. This can be explained by the abovementioned hydration heat, hydration degree, and hydration product structure, and it 
was further verified that TMP organic matter delayed the hydration and hardening of cement. The compressive strength at $3 \mathrm{~d}$ of each cement sample with $0.05 \%$ dosage of admixture are as follows: $\mathrm{TG}>\mathrm{DMO}>\mathrm{TB}>\mathrm{EAC}>$ blank $>$ TMP, which is consistent with the results of hydration heat, hydration degree, and hydration product.

The five kinds of esters have improved the hydration degree of cement and promoted the formation of hydration products and optimized the pore structure. Therefore, it can be concluded that the esters will increase the strength of cement at $28 \mathrm{~d}$. The results in Figure 8(b) confirm this speculation, and as the amount of ester increased, the strength of cement increased significantly (the TB group decreased slightly at the content of $0.1 \%$ ). When the content is $0.05 \%$, the order of the strength of cement hardening slurry is TG $>$ TB $>$ DMO $>$ EAC $>$ TMP $>$ blank, in which TG and $\mathrm{TB}$ increase the cement strength by $6.3 \mathrm{MPa}$ and $5.4 \mathrm{MPa}$, respectively.

\section{Conclusions}

Based on the experimental results, the following conclusions can be drawn:

(1) Ester can make the end time of cement hydration induction longer and delay the occurrence of the second exothermic peak, indicating that it has a delayed effect on the hydration reaction rate of cement at early stage (hydration induction period and acceleration period).

(2) TG, TB, DMO, and EAC increased the second exothermic peak and hydration degree of cement and promoted the formation of hydration products and the optimization of the pore structure. Macroscopic performance is that mechanical properties of cement at $3 \mathrm{~d}$ and $28 \mathrm{~d}$ improved significantly. TMP has a retarding effect on cement and reduces the second exothermic peak of cement and inhibits the formation of early hydration products, which reduces the strength of cement at $3 \mathrm{~d}$, but it improves the strength of cement at $28 \mathrm{~d}$.

(3) The effect of five kinds esters on the hydration and hardening of cement was basically followed by TG> TB $>$ DMO $>$ EAC $>$ TMP. In terms of the molecular structure, for organic compounds containing only ester groups, the higher the number of ester groups, the greater the effect on the hydration of cement. The introduction of other functional groups (such as phosphate or borate) will influence the effect of the esters.

\section{Conflicts of Interest}

The authors declare that there are no conflicts of interest regarding the publication of this paper.

\section{Acknowledgments}

The work described in this paper was fully supported by the scientific and technological projects of Shanxi Province, most through the Research Institute of Concrete and Ecomaterials in China University of Mining and Technology (Beijing) (Project no. MC2014-04).

\section{References}

[1] P. J. Sandberg and F. Doncaster, "On the mechanism of strength enhancement of cement paste and mortar with triisopropanolamine," Cement and Concrete Research, vol. 34, no. 6, pp. 973-976, 2004.

[2] N. Chikh, M. Cheikh-Zouaoui, S. Aggoun, and R. Duval, "Effects of calcium nitrate and isopropanolamine on the setting and strength evolution of Portland cement pastes," Materials and Structures, vol. 41, no. 1, pp. 31-36, 2008.

[3] D. Heinz, M. Goebel, H. Hilbig, L. Urbonas, and G. Bujauskaite, "Effect of TEA on fly ash solubility and early age strength of mortar," Cement and Concrete Research, vol. 40, no. 3, pp. 392-397, 2010.

[4] J. Cheung, A. Jeknavorian, L. Roberts, and D. Silva, "Impact of admixtures on the hydration kinetics of Portland cement," Cement and Concrete Research, vol. 41, no. 12, pp. 1289-1309, 2011.

[5] B. Łaźniewska-Piekarczyk, "The influence of chemical admixtures on cement hydration and mixture properties of very high performance self-compacting concrete," Construction and Building Materials, vol. 49, pp. 643-662, 2013.

[6] W. Jianfeng, Study on Structure-Performance Relationship and Molecular Structure Design of Cement Grinding Aids, China University of Mining and Technology (Beijing), Beijing, China, 2013.

[7] J.-P. Perez, A. Nonat, S. Garrault-Gauffinet, S. Pourchet, and M. Mosquet, "Influence of triisopropanolamine on the physical-chemical and mechanical properties of pure cement pastes and mortars," in Proceedings of 11th International Congress on the Chemistry of Cement (ICCC), pp. 454-463, Durban, South Africa, May 2003.

[8] E. Gartner and D. Myers, "Influence of tertiary alkanolamines on Portland cement hydration," Journal of the American Ceramic Society, vol. 76, no. 6, pp. 1521-1530, 1993.

[9] K. Xiangming, L. Zhenbao, Y. Juan, L. Hui, and W. Dongmin, "Influence of triethanolamine on elemental concentrations in aqueous phase of hydrating cement pastes," Journal of the Chinese Ceramic Society, vol. 41, no. 7, pp. 981-986, 2013.

[10] W. Qisheng and Z. Ying, "Preparation and research of triethanolamine with dibasic organic acid-modified cement grinding aids," Bulletin of the Chinese Ceramic Society, vol. 33, no. 3, pp. 697-707, 2014.

[11] Z. Heren and H. Ölmez, "The influence of ethanolamines on the hydration and mechanical properties of Portland cement," Cement and Concrete Research, vol. 26, no. 5, pp. 701-705, 1996.

[12] J. P. Perez, A. Nonat, S. Garrault, S. Pourchet, and M. Mosquet, "Influence of triisopropanolamine on the physico-chemical and mechanical properties of pure cement pastes and mortars," in Proceedings of the 13th French-Polish Seminar on Reactivity of Solids, pp. S35-S42, Cluny, France, September 2003.

[13] K. Yamada, T. Takahashi, S. Hanehara, and M. Matsuhisa, "Effects of the chemical structure on the properties of the poly carboxylate-type superplasticizer," Cement and Concrete Research, vol. 30, no. 2, pp. 197-207, 2000.

[14] F. Winnefeld, S. Becker, J. Pakusch, and T. Gotz, "Polymer structure/concrete property relations of HRWRA," in Proceedings of the 8th CANMET/ACI International Conference 
on Recent Advances in Concrete Technology, pp. 159-177, Montreal, Québec, Canada, May-June 2006.

[15] F. Winnefeld, A. Zingg, R. Holzer, R. Figi, J. Pakusch, and S. Becker, "Interaction of polycarboxylate-based superplasticizers and cements: influence of polymer structure and C3A-content of cement," in Proceedings of 12th International Congress on the Chemistry of Cement (ICCC), Montreal, Canada, July 2007.

[16] A. O. Habib, I. Aiad, T. A. Youssef, and A. M. Abd El-Aziz, "Effect of some chemical admixtures on the physico-chemical and rheological properties of oil well cement pastes," Construction and Building Materials, vol. 120, pp. 80-88, 2016.

[17] Y. Renhe, L. Baoyuan, and W. Zhongwei, "Study on the pore structure of hardened cement paste by SAXS," Cement Concrete Research, vol. 20, no. 3, pp. 385-393, 1990. 


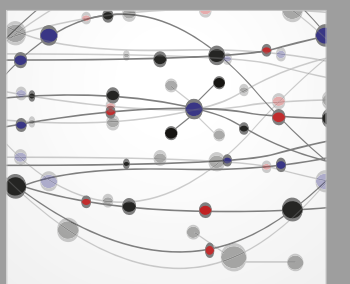

The Scientific World Journal
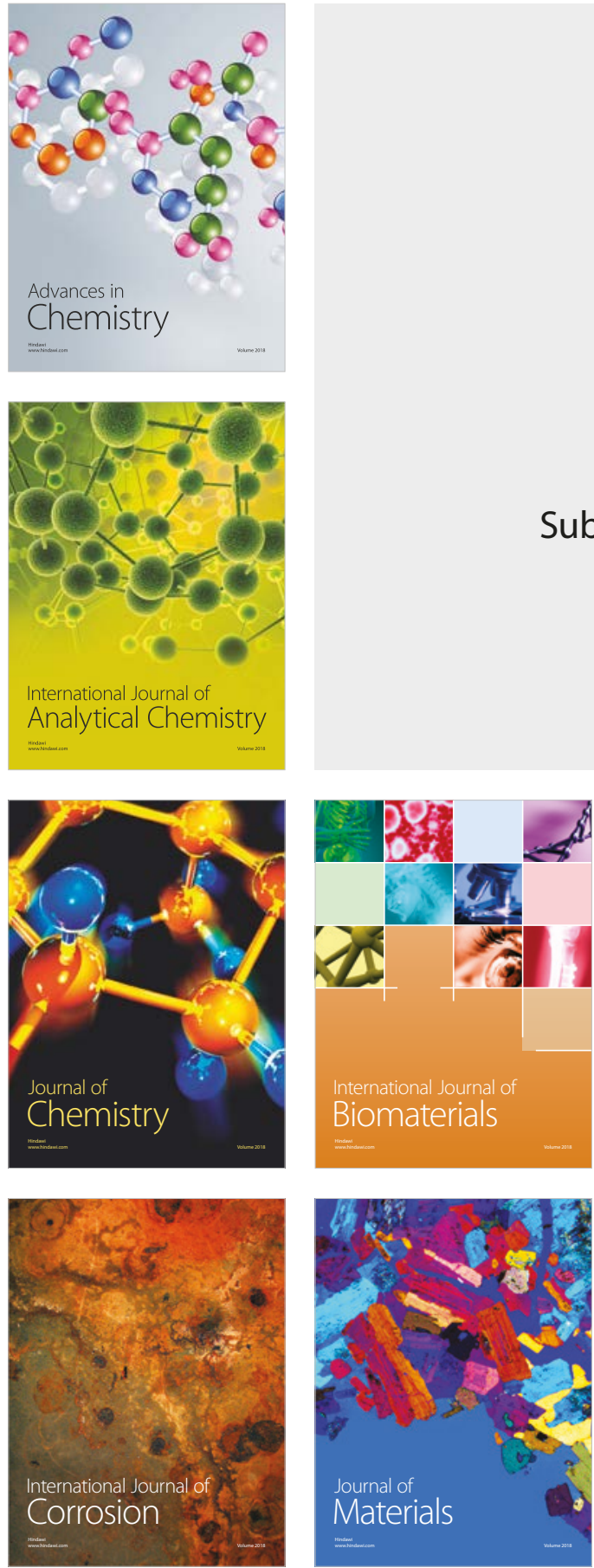

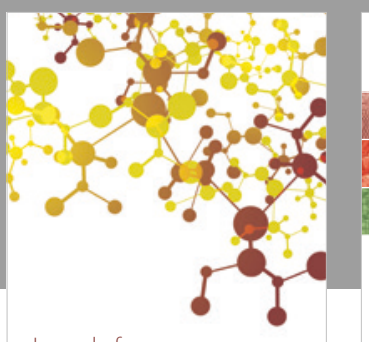

Journal of

Applied Chemistry
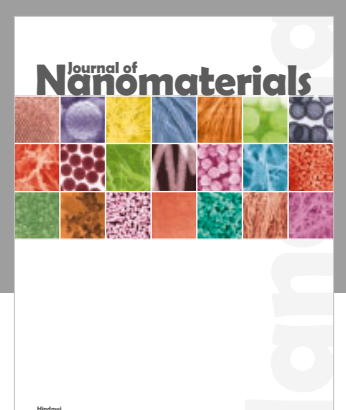

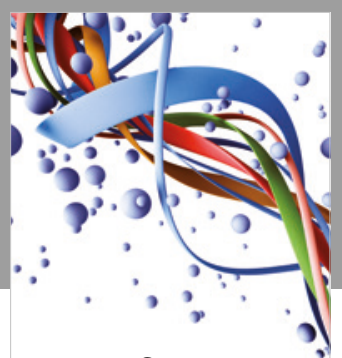

Scientifica

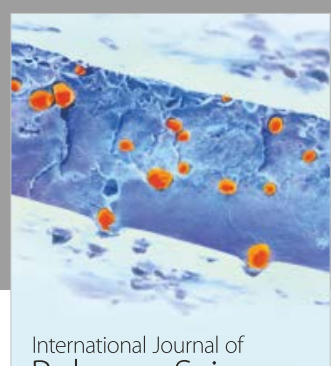

Polymer Science

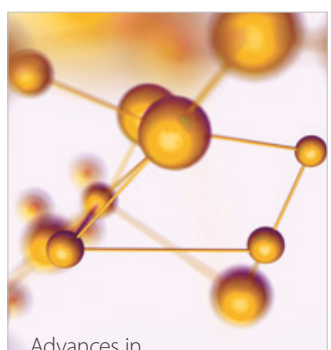

Physical Chemistry
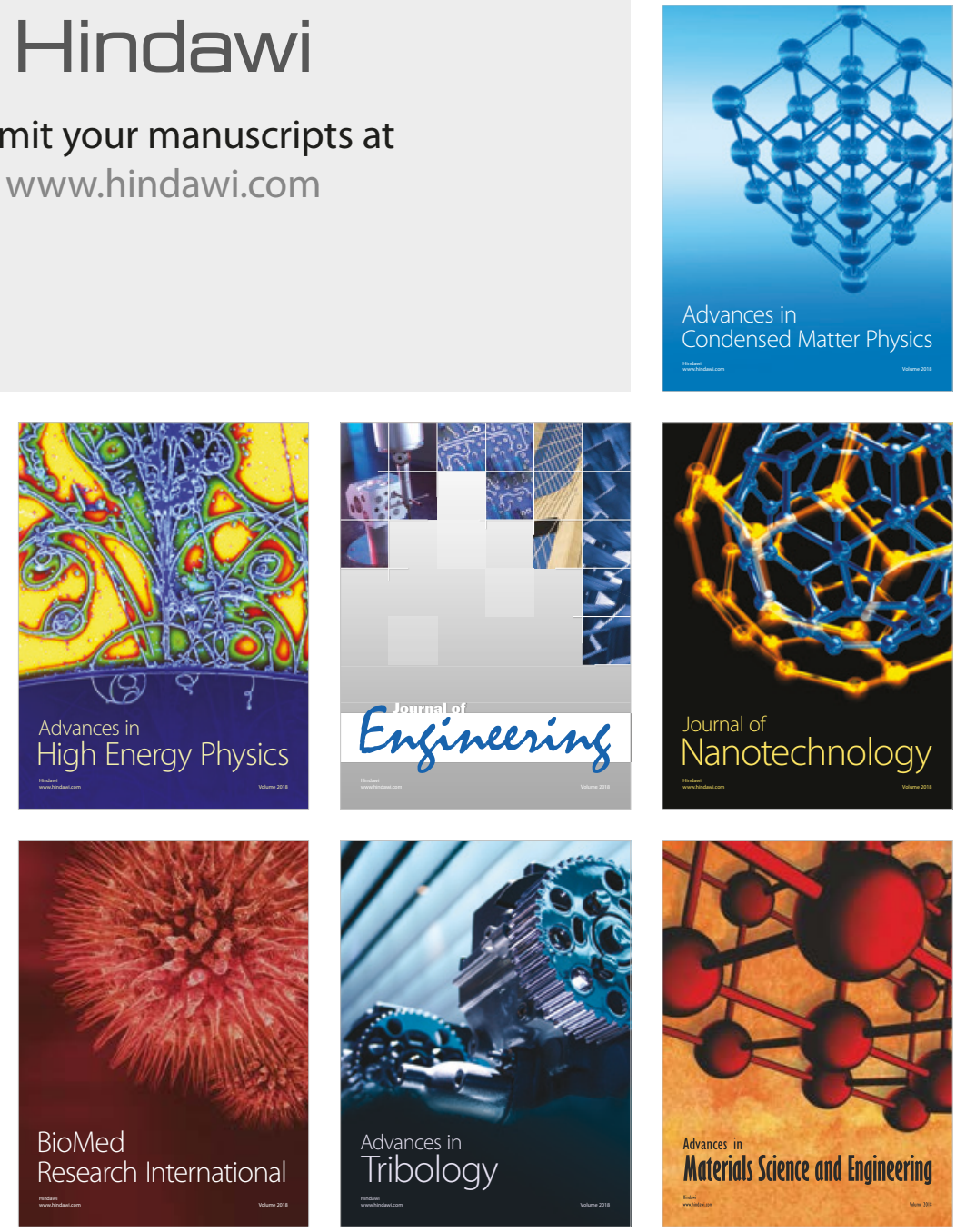